\title{
Effect of varying doses of tamoxifen on ovarian histopathology, serum VEGF, and endothelin I levels in ovarian hyperstimulation syndrome: an experimental study
}

\author{
This article was published in the following Dove Press journal: \\ Drug Design, Development and Therapy \\ 24 March 2015 \\ Number of times this article has been viewed
}

\author{
Șehmus Pala' \\ Remzi Atilgan' \\ Zehra Sema Ozkan' \\ Salih Burçin Kavak' \\ Nevin Ilhan ${ }^{2}$ \\ Nusret Akpolat ${ }^{3}$ \\ Ekrem Sapmaz' \\ 'Department of Obstetrics \\ and Gynecology, ${ }^{2}$ Department \\ of Biochemistry, ${ }^{3}$ Department \\ of Pathology, Firat University \\ School of Medicine, Elazig, Turkey
}

\begin{abstract}
Objective: To examine the effects of low-to-high doses of tamoxifen on ovarian histopathology, serum VEGF, and endothelin 1 levels in ovarian hyperstimulation syndrome (OHSS) in an experimental setting.

Materials and methods: A total of 20 female Wistar albino rats, 22 days of age, were randomly divided into four groups. Follicle-stimulating hormone $10 \mathrm{IU}$ was administered subcutaneously in 15 rats on 4 consecutive days, with OHSS induction on day 5 by 30 IU of human chorionic gonadotropin. Group $1(n=5)$ comprised 35-day-old control rats, group $2(n=5) 35$-day-old OHSS rats, group $3(\mathrm{n}=5)$ 27-day-old OHSS rats receiving $1 \mathrm{mg} / \mathrm{kg}$ of oral tamoxifen for 7 days, group $4(\mathrm{n}=5)$ 27-day-old OHSS rats receiving $3 \mathrm{mg} / \mathrm{kg}$ of oral tamoxifen for 7 days. All rats were decapitated on day 35. Serum VEGF, endothelin 1, and ovarian follicular reserve were assessed in all rats. Kruskal-Wallis variance analysis and the Mann-Whitney $U$-test were used for statistical comparisons. A Bonferroni correction was performed to control the inflation of significance, with a significance level set at a $P$-value of less than 0.025 .

Results: Despite higher serum VEGF, endothelin 1, follicular reserve, and angiogenesis and fibrosis of the corpus luteum in the OHSS group compared to controls, these differences were not significant $(P>0.025$, Mann-Whitney $U$-test $)$. There was a significant reduction in the ovarian follicular reserve in tamoxifen groups compared to controls $(P<0.025$, Mann-Whitney $U$-test), while angiogenesis of the corpus luteum, number of atretic follicles, fibrosis, and serum VEGF were significantly higher in rats receiving tamoxifen $(P<0.025$, Mann-Whitney $U$-test). Also, significantly lower follicular reserve and fibrosis were observed among rats in the lowdose tamoxifen group in comparison with rats in the high-dose tamoxifen group $(P<0.025$, Mann-Whitney $U$-test). No groups had a significant change in endothelin 1 levels $(P>0.025$, Mann-Whitney $U$-test).

Conclusion: Tamoxifen $1 \mathrm{~g}$ and $3 \mathrm{~g}$ resulted in a dose-dependent increase in VEGF and endothelin 1 levels, and ovarian follicle reserves were significantly reduced in our experimental model.
\end{abstract}

Keywords: low-to-high doses of tamoxifen, OHSS, cystic enlargement of the ovaries, hCG

\section{Introduction}

Ovarian hyperstimulation syndrome (OHSS) is characterized by cystic enlargement of the ovaries and rapid fluid shifts from the intravascular compartment to the third space, which is an iatrogenic complication of stimulation for assisted reproductive technology and ovulation induction. In its severe form, OHSS is a potentially life-threatening condition, and it is reported that $1.9 \%$ of cases need hospitalization. Exogenous or endogenous
Correspondence: Remzi Atilgan Department of Obstetrics and Gynecology, Firat University School of Medicine, Elazig 23119, Turkey Tel +904242 2333555

Email remzi_atilgan@hotmail.com 
human chorionic gonadotropin (hCG) is the triggering factor of the syndrome. The effect of human chorionic gonadotropin (hCG) on OHSS is thought to mediate the production of the angiogenic molecule VEGF. ${ }^{1}$ This iatrogenic case can effect $12 \%-25 \%$ of in vitro fertilization cycles, and the severe forms of OHSS can be seen in $0.5 \%-5 \%$ of assisted reproductive technology cycles. Since OHSS is a potentially life-threatening condition and its pathophysiology difficult to understand, it has been extensively studied by investigators. ${ }^{2}$ After ovulationinduction treatment, cytokines including interleukins, factors belonging to the renin angiotensin system, TNF $\alpha$, VEGF, and endothelin 1 are thought to induce increased vascular permeability. ${ }^{3}$ In experimental animal models, the addition of hCG to in vivo treatment with gonadotropins has been shown to result in increased vascular permeability. On the other hand, the addition of specific VEGF inhibitors or blockage of VEGFreceptor expression by a dopamine agonist can restore normal vascular permeability. ${ }^{4,5}$ The main pathophysiology that underlies that clinical situation is increased vascular permeability. Administration of hCG significantly raises VEGF and VEGFR2, and this results in increased vascular permeability. ${ }^{6}$ High levels of endothelin 1 have been detected in follicular fluid samples from patients undergoing ovulation induction. Furthermore, a positive correlation between follicular fluid endothelin 1 and follicle-stimulating hormone (FSH) has been found, suggesting a role of endothelin 1 not only in ovarian functions but also in the pathogenesis of OHSS.

Tamoxifen is a selective ER modulator. Tamoxifen binds competitively to ER, blocking the mitogenic effect of estradiol so that its antiproliferative action occurs, and this is tamoxifen's main therapeutic strength. Recently, clinical studies of tamoxifen displayed its antiangiogenic and VEGF-reducing ability in various tumor models. ${ }^{8}$ Although it is important in the treatment of breast cancer, long-term tamoxifen use is reported to increase intracellular VEGF levels and to be responsible for metastasis and angiogenesis, resulting in inferior outcomes. ${ }^{9}$ In another study, it was reported that tamoxifen decreased VEGF levels in vitro and in vivo by inducting an antiangiogenic response. ${ }^{10}$

In light of this information suggesting a potential preventive and therapeutic role for this selective ER modulator, we decided to examine the role of tamoxifen on ovarian follicular reserve (OFR), VEGF, and endothelin 1 for the treatment of experimentally induced OHSS in rats.

\section{Materials and methods Experimental design}

In this study undertaken at the Animal Experimentation Laboratory of the Medical Faculty of Firat University a total of 20 immature female Wistar albino rats, 22 days of age and weighing between 41 and $49 \mathrm{~g}$, were used. The study protocol was approved by the ethics committee of the Medical Faculty of Firat University. During the study period, rats were kept in separate cages, each containing five rats, and were exposed to 12-hour cycles of light and darkness. Rats were given food pellets and tap water. Weight and hematocrit of all rats were recorded on the initial day of study (day 0). A total of 15 randomly selected rats were given subcutaneous injections of FSH 10 IU on 4 consecutive days, with induction of ovarian hyperstimulation through the use of 30 IU of hCG on day 5. The validity of the OHSS model in rats was demonstrated by Ohba et al by an increase in weight and hematocrit values. ${ }^{11}$ After OHSS induction (day 6), these rats were randomly allocated into three groups, yielding a total of four groups: group $1(\mathrm{n}=5), 35$-day-old control group (agematched group); group $2(\mathrm{n}=5)$, OHSS rats decapitated at age 35 days without any intervention; group $3(n=5), 27$-day-old OHSS rats that were decapitated following oral administration of $1 \mathrm{mg} / \mathrm{kg}$ of tamoxifen (Nolvadex, AstraZeneca, UK) for 7 days $(27+7$ day $1 \mathrm{mg} / \mathrm{kg}$ of tamoxifen, decapitation on day 35); and group $4(n=5), 27$-day old OHSS rats that were decapitated following oral administration of $3 \mathrm{mg} / \mathrm{kg}$ of tamoxifen $(27+7$ days of $3 \mathrm{mg} / \mathrm{kg}$ of tamoxifen, decapitation on day 35$)$.

In all study groups, hematocrit and weight measurements were performed on day 13 and decapitation performed on day 35 under general anesthesia by intraperitoneal administration of ketamine $(75 \mathrm{mg} / \mathrm{kg})$ and xylazine $(10 \mathrm{mg} / \mathrm{kg})$.

\section{Enzyme-linked immunosorbent assay}

Approximately $3 \mathrm{~mL}$ of blood sample was obtained from each rat decapitated. Sera were separated by centrifugation of blood samples at 2,500 rpm for 4 minutes and kept at $-20^{\circ} \mathrm{C}$ until VEGF and endothelin 1 assays. VEGF was assayed using a mouse VEGF enzyme-linked immunosorbent assay kit (ELM-VEGF-001; RayBio, USA) and endothelin was measured using an endothelin 1 E/Kit (EK-023-01; Phoenix Pharmaceuticals, USA).

\section{Ovarian morphology}

After laparotomy, ovaries were removed and cleaned of adhering tissue in culture medium, weighed, and used for subsequent assays. Ovarian tissue was fixed with $10 \%$ formaldehyde, and then paraffin-embedded tissue samples were cut into $4 \mu \mathrm{m}$ cross sections for estimation of mean ovarian follicle count. The sections were stained with Masson's trichrome to determine OFR under light microscopy (Olympus BX-50). 
The $4 \mu \mathrm{m}$-thick cross sections were mounted at $50 \mu \mathrm{m}$ intervals onto microscope slides to prevent counting of the same structure twice, according to a previously described method. ${ }^{12}$ Follicles were classified as primordial, primary, secondary, and tertiary. An atretic follicle (AF) was defined as a follicle presenting more than ten pyknotic nuclei; for the smallest follicles, the criteria for atresia were a degenerate oocyte, precocious antrum formation, or both. ${ }^{13}$

\section{Main outcome measures}

The main outcome measures were age (days), weight (g), hematocrit $(\%)$, weight of ovaries $(\mathrm{mg})$, serum levels of VEGF (pg/mL) and endothelin $1(\mathrm{ng} / \mathrm{mL})$, and total follicle count with determination of primordial, primary, secondary, and tertiary follicle numbers. ${ }^{14}$ AFs and corpus luteum (CL) and corpus albicans changes were also determined. The CL was examined for signs of regression of angiogenesis and ovarian stromal fibrosis, which were graded as follows: $0=$ absent, $1=$ moderately present, and $2=$ highly present . Ovarian follicle cysts were counted macroscopically and scaled as $0=$ absent and $1=$ present $^{15}$

\section{Statistical analyses}

Analyses were performed using SPSS 9.0. Between-group differences for the comparison of statistical parameters were examined using the Kruskal-Wallis analysis of variance. For parameters with $P<0.05$, pair-wise comparisons were used using the Mann-Whitney $U$-test. A Bonferroni correction was performed, and $P$-values under 0.025 were considered significant.

\section{Results}

Experimental procedures were accomplished successfully in all four groups. Table 1 depicts the means and standard deviation for the parameters tested in the study groups. A comparison between groups 1 and 2 showed significantly higher total ovarian weight, as well as significantly higher body weight and hematocrit on days 6 and 3 in group 2 $(P<0.025$, Mann-Whitney $U$-test). OFR was significantly lower in group 3 than in group 1 (Figure 1B). Also, rats in group 3 had significantly increased CL and total corpus numbers, angiogenesis of $\mathrm{CL}$, number of AFs, serum VEGF levels, ovarian weight, total weight at days 6 and 13, and hematocrit on day 6 . Rats in group 4 had significantly increased CL and total corpus numbers, angiogenesis of CL, number of AFs, fibrosis (Figure 1C), serum VEGF levels, ovarian weight, total weight at days 6 and 13, and hematocrit on day 6 (Table 1). Rats in group 3 had significantly higher serum VEGF than those in group 2. However, hematocrit at day 13 was significantly lower. Rats in group 4 had significantly higher serum VEGF and weight on day 6, while they had significantly lower hematocrit at day 13 compared to rats in group 2. Significantly lower OFR, fibrosis, and weight at days 6 and 13 were detected in group 3 than in group 4 .

\section{Discussion}

A cause-and-effect relationship has not been firmly established between fertility treatments and OHSS, leading to continuing search for possible mechanisms. In this regard, our aim was to examine the association between OHSS and VEGF and endothelin 1 levels, as well as the effect of tamoxifen, on these parameters. In order to prevent or minimize age-related differences, age-matched rats were used for the study.

VEGF is an important mediator for OHSS. It stimulates angiogenesis through VEGF2 receptors on endothelial cells and increases vascular hyperpermeability. ${ }^{16}$ Administration of hCG significantly raises VEGF and VEGFR2, and this results in increased vascular permeability. ${ }^{6}$ On the other hand, hypoxia represents the most important stimulating factor for the production of VEGF, which is considered to play a major role in increased vascular permeability. ${ }^{17}$ This is achieved by the transactivation of hypoxia-inducible factor I, which binds to the promoter of the VEGF gene. ${ }^{18}$ Clomiphene citrate and tamoxifen are nonsteroidal selective ER modulators. Clomiphene citrate has been the first-line method of ovulation induction, but tamoxifen has also been used to induce ovulation. Differently from clomiphene, it has been reported that tamoxifen acts as an agonist on the ERs of the endometrium and vaginal mucosa. ${ }^{19}$

Tamoxifen has been reported to play an important role in the regulation of angiogenic factors, such as VEGF, in both breast cancer and normal target tissues. ${ }^{20}$ It has been reported that the combination of hypoxia and estrogen may be important in upregulating VEGF in some breast cancers. ${ }^{21}$ Bausero et al reported that tamoxifen increased VEGF expression in venous smooth-muscle cells and exerted estrogen-like effects in the vascular system. ${ }^{18}$ Furthermore, Donovan et al proposed additional effects of tamoxifen on angiogenesis that occur in conjunction with decreased levels of the proangiogenic cytokine VEGF. ${ }^{22}$ In contrast, other authors have reported an agonistic effect of tamoxifen on VEGF expression, despite antagonistic effects on tumor growth. ${ }^{9}$ Tamoxifen has been shown to induce angiogenesis by increased expression of VEGF messenger ribonucleic acid in rat uterus. ${ }^{23}$ 
Table I Weight, hematocrit (\%), ovarian weight, ovarian histopathology, follicle counts, serum VEGF, and endothelin I levels of all rats in the study

\begin{tabular}{|c|c|c|c|c|}
\hline Parameters & Group I & Group 2 & Group 3 & Group 4 \\
\hline Weight on day 0 (g) & $47 \pm 16.8^{a}$ & $45.6 \pm 2.8^{\mathrm{a}}$ & $45 \pm 1.5^{\mathrm{a}}$ & $48.2 \pm 0.8^{\mathrm{a}}$ \\
\hline Weight on day $6(\mathrm{~g})$ & $61.4 \pm 2.3^{\mathrm{a}}$ & $71.8 \pm 2.1^{b}$ & $7 I \pm 5^{b}$ & $82 \pm 1.6^{c}$ \\
\hline Weight on day 13 (g) & $83.6 \pm 1.1^{a}$ & $105.6 \pm 3.6^{\mathrm{b}, \mathrm{c}}$ & $98 \pm 4.5^{\mathrm{b}}$ & $107.8 \pm 4.5^{c}$ \\
\hline Hematocrit on day $0(\%)$ & $37.6 \pm 1.5^{a}$ & $30.2 \pm 14.1^{\mathrm{a}}$ & $37.4 \pm 1.9^{\mathrm{a}}$ & $36.6 \pm 2.8^{\mathrm{a}}$ \\
\hline Hematocrit on day $6(\%)$ & $40 \pm 1.8^{\mathrm{a}}$ & $45.2 \pm 0.8^{b}$ & $43.8 \pm 0.4^{b}$ & $44 \pm 1.6^{b}$ \\
\hline Hematocrit on day I3 (\%) & $38.2 \pm 1.3^{\mathrm{a}}$ & $42.2 \pm 0.8^{b}$ & $38.4 \pm 2.1^{\mathrm{a}}$ & $40.2 \pm \mathrm{I} . \mathrm{I}^{\mathrm{c}}$ \\
\hline Ovarian weight (mg) & $60.6 \pm 5.8^{\mathrm{a}}$ & $123 \pm 18.2^{b}$ & $101 \pm 13^{b}$ & $120.4 \pm 19.4^{b}$ \\
\hline Ovarian follicle reserve & $49.4 \pm 7.6^{\mathrm{a}}$ & $45 \pm I I . I^{a, b}$ & $33.6 \pm 4.8^{\mathrm{b}}$ & $45.4 \pm 6.5^{\mathrm{a}}$ \\
\hline$C L$ count & $0^{\mathrm{a}}$ & $1.8 \pm 1.8^{\mathrm{a}, \mathrm{b}}$ & $3.4 \pm 3.2^{\mathrm{b}}$ & $3 \pm 2.3^{b}$ \\
\hline Total corpus count & $0^{\mathrm{a}}$ & $1.8 \pm 1.8^{\mathrm{a}, \mathrm{b}}$ & $3.4 \pm 3.2^{\mathrm{b}}$ & $3 \pm 2.3^{b}$ \\
\hline Angiogenesis in $\mathrm{CL}$ & $0^{\mathrm{a}}$ & $0.4 \pm 0.5^{\mathrm{a}, \mathrm{b}}$ & $1.2 \pm 0.4^{b}$ & $1.4 \pm 0.5^{\mathrm{b}}$ \\
\hline Fibrosis & $0^{\mathrm{a}}$ & $0.4 \pm 0.5^{\mathrm{a}, \mathrm{b}}$ & $0^{\mathrm{a}}$ & $0.8 \pm 0.4^{b}$ \\
\hline Atretic follicle count & $0.4 \pm 0.5^{\mathrm{a}}$ & $2.6 \pm 2^{a, b}$ & $2.6 \pm 1.3^{b}$ & $2 \pm 0.7^{\mathrm{b}}$ \\
\hline VEGF $(p g / m L)$ & $1,596 \pm 1,113^{a}$ & $2,250 \pm 952^{\mathrm{a}}$ & $5,482 \pm 790.3^{b}$ & $7,015 \pm 220.2^{\circ}$ \\
\hline Endothelin I (ng/mL) & $0.8 \pm 0.1^{\mathrm{a}}$ & $0.9 \pm 0.1^{\mathrm{a}}$ & $1.2 \pm 0.4^{\mathrm{a}}$ & $1.3 \pm 0.5^{\mathrm{a}}$ \\
\hline
\end{tabular}

Note: ${ }^{\mathrm{a}-\mathrm{c} D}$ ifferences between the groups $(P<0.025$, Mann-Whitney U-test). Data are shown as mean $\pm \mathrm{SD}$.

Abbreviation: CL, corpus luteum.

In this study, all rats in the OHSS groups had increased VEGF levels, particularly in group 4. Due to a hypoxic effect triggered by tamoxifen in the OHSS groups, we believe that tamoxifen may have been responsible for the significant increase in VEGF levels in groups 3 and 4 compared to group 2. Also, it is likely that the increased weight in rats in group 4 on days 6 and 13 as compared to those in group 3 might have resulted from the effect of VEGF.

Increased production of VEGF, both in human ovaries and fallopian tubes, has been detected under hypoxic conditions. It also leads to increased vascular permeability and regulates lumen secretion. Increased vascular permeability
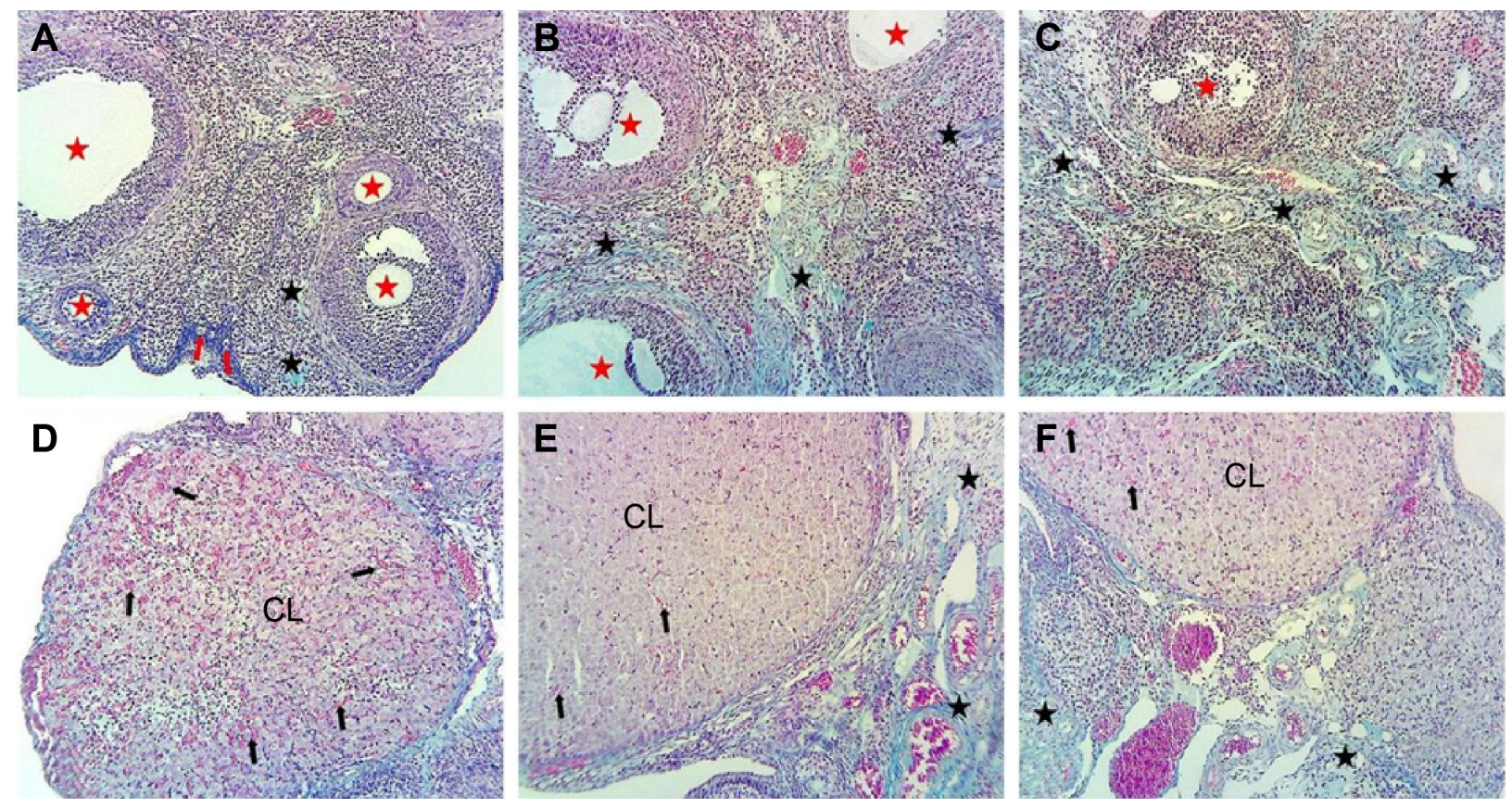

Figure I Masson's trichrome staining of ovarian tissues examined under light microscopy.

Notes: (A) OFR elements in group I. (B) Decreased OFR elements and increased fibrosis in group 3. (C) Reduced OFR and increased fibrosis in group 4. (D) Angiogenesis of $\mathrm{CL}$ in group 2. (E) Reduced angiogenesis of $\mathrm{CL}$ in group 3. (F) Reduced angiogenesis of $\mathrm{CL}$ and patchy areas of fibrosis in group 2. Red stars, different follicle types; black stars, areas of fibrosis; black arrows, angiogenesis; red arrows, primordial follicle.

Abbreviations: OFR, ovarian follicular reserve; $\mathrm{CL}$, corpus luteum. 
of the ovaries causes the fluid collection observed in ovarian cysts. ${ }^{17}$ The higher VEGF levels in groups 3 and 4 compared to other study groups may not only have been associated with already existing hypoxia in OHSS but also with the antiangiogenic effects of tamoxifen.

Another parameter examined in our study was the OFR in OHSS. OFR was significantly reduced in groups 3 and 4. This observation is in line with a previous report, which suggested that OHSS triggers a cascade of hypoxic events and that the use of antiangiogenic medications may result in decreased OFR through further aggravation of hypoxia. ${ }^{24}$ Ovulation-induction agents, such as hCG and luteinizing hormone ( $\mathrm{LH})$, have been shown to increase the numbers of VEGFR1 and -2, and gonadotropin-releasing hormone analogs may alleviate OHSS through an inhibitory effect on this mechanism. ${ }^{25}$ In our study, increased levels of VEGF were observed in rats in which OHSS was induced by gonadotropin and hCG, with maximum concentrations of VEGF in groups 3 and 4, which had more intense hypoxia. However, other authors have argued against the role of VEGF in hyperpermeability, despite its presence in serum samples from OHSS patients as a result of ovarian production. ${ }^{26}$ This report is at odds with our results.

Angiogenesis in the ovaries occurs under the influence of both endocrine factors, such as hCG and progesterone, and paracrine factors. ${ }^{27}$ In our experimental model, angiogenesis of the CL was significantly more marked in group 2 and in rats experiencing deeper hypoxia due to tamoxifen compared to group 1. This both leads to reduced OFR and clearly demonstrates the association between VEGF, angiogenesis, and hypoxia. Similarly, in their study with guinea pigs, McClure et al administered human-derived anti-VEGF sera to animals in which OHSS was induced, and observed $70 \%-80 \%$ decreased vascular permeability. ${ }^{28}$ In addition to our results, these findings may also be considered as further evidence for the hypoxia-inducing role of VEGF in OHSS. In our study, all rats in the OHSS groups had increased levels of VEGF. McElhinney et al proposed that the reported variability of VEGF concentrations in different sets of OHSS patients may be due to the presence of serum proteins that inactivate or remove VEGF. ${ }^{29}$ This may explain the difference between our findings and other reports suggesting no effect for VEGF in OHSS.

Endothelin 1 is a potent vasoconstrictor that may lead to increased capillary permeability in a number of different tissues. High concentrations of endothelin 1 were observed in patients undergoing ovulation induction. Follicular fluid samples have been found to have 100- to 300-fold higher concentrations of endothelin 1 compared to plasma, with a positive correlation between endothelin and FSH, suggesting a potential role for endothelin 1 in OHSS. ${ }^{7}$ In our study, consistent with previous reports, OHSS rats had higher endothelin 1 levels compared to controls, despite the absence of statistical significance for the difference. This may suggest that in contrast with VEGF, endothelin 1 may not play a major role in the pathogenesis of OHSS. However endothelin 1 may represent a homeostatic response to maintain blood pressure rather than being an initiator of the syndrome. ${ }^{7}$

Tamoxifen, similarly to clomiphene citrate, has an antiestrogenic effect, but does not result in FSH and LH elevations adequate for follicle formation. Although success rates close to that of clomiphene citrate have been reported for tamoxifen, it is generally not used, due to its negative effects on endometrial tissues. While tamoxifen is antiestrogenic on breast tissue, it can cause endometrial stimulation and thus endometrial cancer on the endometrium. ${ }^{30}$ Our decision to administer different doses of tamoxifen (ie, 1 and $3 \mathrm{~g}$ ) in this study was based on the differential effects of different tamoxifen doses previously reported. ${ }^{26}$ In our study, increased tamoxifen doses were associated with increased serum VEGF serum levels. In other words, in group 4, receiving higher doses of tamoxifen, there was significantly more marked hypoxia, probably due to the antiangiogenic properties of tamoxifen.

In patients at increased risk of OHSS and reduced OFR, caution should be exercised not to induce this condition by the use of agents that have a similar mechanism of action to tamoxifen. Another method of ovulation induction should be preferred in such patients, due to the increased risk of hypoxia and OHSS associated with decreased OFR.

In conclusion, $1 \mathrm{~g}$ and $3 \mathrm{~g}$ tamoxifen resulted in a dosedependent increase in VEGF and endothelin 1 levels, and OFR levels were significantly reduced in our experimental model.

\section{Disclosure}

The authors report no conflicts of interest in this work.

\section{References}

1. Humaidan P, Quartarolo J, Papanikolaou EG. Preventing ovarian hyperstimulation syndrome: guidance for the clinician. Fertil Steril. 2010;94:389-400.

2. Naredi N, Talwar P, Sandeep K. VEGF antagonist for the prevention of ovarian hyperstimulation syndrome: current status. Med J Armed Forces India. 2014;70:58-63.

3. Elchalal U, Schenker JG. The pathophysiology of ovarian hyperstimulation syndrome - views and ideas. Hum Reprod. 1997;12:1129-1137.

4. Fraser HM, Duncan WC. SRB Reproduction, Fertility and Development Award Lecture 2008. Regulation and manipulation of angiogenesis in the ovary and endometrium. Reprod Fertil Dev. 2009;21:377-392. 
5. Soares SR. Etiology of OHSS and use of dopamine agonists. Fertil Steril. 2012;97:517-522.

6. Gómez R, Soares SR, Busso C, Garcia-Velasco JA, Simón C, Pellicer A. Physiology and pathology of ovarian hyperstimulation syndrome. Semin Reprod Med. 2010;28:448-457.

7. Schenker JG. Clinical aspects of ovarian hyperstimulation syndrome. Eur J Obstet Gynecol Reprod Biol. 1999;85:13-20.

8. Kumar BN, Rajput S, Dey KK, et al. Celecoxib alleviates tamoxifeninstigated angiogenic effects by ROS-dependent VEGF/VEGFR2 autocrine signaling. BMC Cancer. 2013;3:273.

9. Ruohola JK, Valve EM, Karkkainen MJ, Joukov V, Alitalo K, Härkönen PL. Vascular endothelial growth factors are differentially regulated by steroid hormones and antiestrogens in breast cancer cells. Mol Cell Endocrinol. 1999;149:29-40.

10. Darakhshan S, Bidmeshkipour A, Khazaei M, Rabzia A, Ghanbari A. Synergistic effects of tamoxifen and tranilast on VEGF and MMP-9 regulation in cultured human breast cancer cells. Asian Pac J Cancer Prev. 2013;14:6869-6874.

11. Ohba T, Ujioka T, Ishikawa K, Tanaka N, Okamura H. Ovarian hyperstimulation syndrome-model rats; the manifestation and clinical implication. Mol Cell Endocrinol. 2003;28:47-52.

12. Woodruff TK, D'Agostino J, Schwartz NB, Mayo KE. Dynamic changes in inhibin messenger RNAs in rat ovarian follicles during the reproductive cycle. Science. 1988;239:1296-1299.

13. Andreu C, Parborell F, Vanzulli S, Chemes H, Tesone M. Regulation of follicular luteinization by a gonadotropin-releasing hormone agonist: relationship between steroidogenesis and apoptosis. Mol Reprod Dev. 1998:51:287-294.

14. Souza AZ, Fonseca AM, Izzo VM, Clauzet RM, Salvatore CA. Ovarian histology and function after total abdominal hysterectomy. Obstet Gynecol. 1986;68:847-849.

15. Atilgan R, Kavak SB, Celik A, Sapmaz E, Akpolat N, Boztosun A. The effects of tubal segmental excision on ovarian histopathological examination in the rats: an experimental study. Turk Klin J Gynecol Obstet. 2009;19:335-341.

16. Chen SU, Chou CH, Lee H, Ho CH, Lin CW, Yang YS. Lysophosphatidic acid up-regulates expression of interleukin-8 and -6 in human granulosa-lutein cells through LPA receptors and NF- $\kappa B$ dependent pathways: implications for angiogenesis of corpus luteum and ovarian hyperstimulation syndrome. J Clin Endocrinol Metab. 2008;93:935-943.

17. Abulafia O, Sherer DM. Angiogenesis of the ovary. Am J Obstet Gynecol. 2000;182:240-246.

18. Bausero P, Ben-Mahdi M, Mazucatelli J, Bloy C, Perrot-Applanat M. Vascular endothelial growth factor is modulated in vascular muscle cells by estradiol, tamoxifen, and hypoxia. Am J Physiol Heart Circ Physiol. 2000;279:H2033-H2042.
19. Steiner AZ, Terplan M, Paulson RJ. Comparison of tamoxifen and clomiphene citrate for ovulation induction: a meta-analysis. Hum Reprod. 2005;20:1511-1515.

20. Bogin L, Degani H. Hormonal regulation of VEGF in orthotopic MCF7 human breast cancer. Cancer Res. 2002;62:1948-1951.

21. Maity A, Sall W, Koch CJ, Oprysko PR, Evans SM. Low $\mathrm{pO}_{2}$ and betaestradiol induce VEGF in MCF-7 and MCF-7-5C cells: relationship to in vivo hypoxia. Breast Cancer Res Treat. 2001;67:51-60.

22. Donovan D, Harmey JH, Redmond HP, Bouchier-Hayes D. Ascites revisited: a novel role for tamoxifen. Eur J Surg Oncol. 1997;23:570.

23. Hayder SM, Chiappetta C, Stancel GM. Triphenylethylene antiestrogens induce uterine vascular endothelial growth factor expression via their partial estrogen agonist activity. Cancer Lett. 1997;120:165-171.

24. Abramov Y, Elchalal U, Schenker JG. Pulmonary manifestations of severe ovarian hyperstimulation syndrome: a multicenter study. Fertil Steril. 1999;71:645-651.

25. Kitajima Y, Endo T, Manase K, Nishikawa A, Shibuya M, Kudo R. Gonadotropin-releasing hormone agonist administration reduced vascular endothelial growth factor (VEGF), VEGF receptors, and vascular permeability of the ovaries of hyperstimulated rats. Fertil Steril. 2004;81:842-849.

26. Kobayashi H, Okada Y, Asahina T, Gotoh J, Terao T. The kallikreinkinin system, but not vascular endothelial growth factor, plays a role in the increased vascular permeability associated with ovarian hyperstimulation syndrome. J Mol Endocrinol. 1998;20:363-374.

27. Enskog A, Henriksson M, Unander M, Nilsson L, Brännström M. Prospective study of the clinical and laboratory parameters of patients in whom ovarian hyperstimulation syndrome developed during controlled ovarian hyperstimulation for in vitro fertilization. Fertil Steril. 1999;71:808-814.

28. McClure N, Healy DL, Rogers PA, et al. Vascular endothelial growth factor as capillary permeability agent in ovarian hyperstimulation syndrome. Lancet. 1994;344:235-236.

29. McElhinney B, Ardill J, Caldwell C, Lloyd F, McClure N. Variations in serum vascular endothelial growth factor binding profiles and the development of ovarian hyperstimulation syndrome. Fertil Steril. 2002;78:286-290.

30. Goldstein SR, Siddhanti S, Ciaccia AV, Plouffe L Jr. A pharmacological review of selective oestrogen receptor modulators. Hum Reprod Update. 2000;6:212-224.
Drug Design, Development and Therapy

\section{Publish your work in this journal}

Drug Design, Development and Therapy is an international, peerreviewed open-access journal that spans the spectrum of drug design and development through to clinical applications. Clinical outcomes, patient safety, and programs for the development and effective, safe, and sustained use of medicines are a feature of the journal, which

\section{Dovepress}

has also been accepted for indexing on PubMed Central. The manuscript management system is completely online and includes a very quick and fair peer-review system, which is all easy to use. Visit http://www.dovepress.com/testimonials.php to read real quotes from published authors. 